\title{
The Complexation of Lanthanides by Azo-B-Diketones Stability Constants
}

\author{
by
}

\author{
M. S. Abdel-Moez, G. A. El-Anani, A. A. Ramadan* and B. A. El-Shetary* \\ Department of Chemistry, Faculty of Science, Qatar University, \\ Doha, Qatar.
}

\begin{abstract}
The stability constants of the complexes between the trivalent lanthanide series of cations and series of azo-B-diketone ligands are reported. The measurements were conducted at $30^{\circ} \mathrm{C}$ and zero ionic strength (free $\mathrm{KNO}_{3}$ ), in $100 \%$ methanol. The relation between the overall stability constant $\left(\log B_{2}\right)$ and atomic number of lanthanide elements, shows a gadolinium-break. The relation between $\left(\log B_{2}\right)$ and the basicity of the studied ligands $\left(\Sigma \mathrm{pK}_{1}+\mathrm{pK}_{2}\right)$ are, also discussed. The overall stability values obtained reflected a great affinity of the organic ligands for chelation with lanthanide ions.
\end{abstract}

* Department of Chemistry, Faculty of Education, Ain-Shams University, Cairo, Egypt 


\section{Introduction}

The chelation between B-diketones and tervalent lanthanide ions were studied ${ }^{(1.2)}$ No work was done concerning the carboxyphenylhydrazo-diketones and similar ligands. Therefore in the present investigation the overall stability constants of an interest tridentate organic ligand and tervalent lanthanide ions have been measured potentiometically.

The ligands choosen for study were :

2-Carboxyphenylhydrazoacetone (2-CPHAA),

2-Carboxyphenylhydrazobenzoylacetone (2-CPHBA),

3-Carboxyphenylhydrazodiethylmalonate (2-CPHDEM) and

4-Carboxyphenylhydrazodiethylmalonate (3-CPHDEM).

\section{Experimental}

The organic ligands used in this investigation were synthesized by coupling the diazonium salt of anthranilic acid with acetylacetone, benzoylacetone and diethylmalonate in sodium acetate medium. The formulae of the ligands were checked by elemental analysis and their I. R. spectra were also investigated.

The nitrate of lanthanide elements were prepared from the corresponding oxides (B. D. H., $99.9 \%$ ). The exact concentration of each metal ion was determined by titration against EDTA using xylenol orange as indicator. Potassium hydroxide solution was prepared by dissolving a concentrated-carbonate free-potassium hydroxide solution in methanol. The $\mathrm{KOH}$ solution was standardized against potassium hydrogen phthalate.

pH-metric titrations were carried out using "Beckman-SSR-2" pH-meter fitted with combined electrodes. The titration were carried out in double jacketed cell at constant temperature of $+0.1^{\circ} \mathrm{C}$ in atmosphere of purified nitrogen. The $\mathrm{pH}$-meter was calibrated using standard B.D.H. buffered solution. A mixture containing $5 \times$ $10^{-3} \mathrm{M}$ ligand and $2.5 \times 10^{-3} \mathrm{M}$ metal ion in methanol was titrated against potassium hydroxide. The $\mathrm{pH}$ of each solution was measured after each addition of $0.05 \mathrm{ml}$ of base. All titrations were repeated at least two times and agreement between the $\mathrm{pH}$ reading of different titrations was usually within \pm 0.02 . The solutions were continuoưsty stirred by bubbling of purified nitrogen. 


\section{Method of Calculation}

The acid dissociation constants and the stability constants of the complexes formed between these ligands and some transition elements was discussed else where $^{(3)}$. The acid dissociation constants of the ligands were calculated using direct algebratic method ${ }^{(4)}$. The equilibrium and the dissociation constants involved are :

$$
\begin{aligned}
& \mathrm{H}_{2} \mathrm{~A} \stackrel{\mathrm{Ka}_{1}}{\rightleftharpoons} \mathrm{HA}^{-}+\mathrm{H}^{1^{+}} \\
& \mathrm{Ka}_{1}=\left[\mathrm{H}^{+}\right]\left[\mathrm{HA}^{-}\right] /\left[\mathrm{H}_{2} \mathrm{~A}\right] \\
& \mathrm{HA}^{-} \stackrel{\mathrm{Ka}_{2}}{\rightleftharpoons} \mathrm{A}^{2-}+\mathrm{H}^{+} \\
& \mathrm{Ka}_{2^{-}}=\left[\mathrm{A}^{2-}\right]\left[\mathrm{H}^{+}\right] /[]
\end{aligned}
$$

where $\mathrm{Ka}_{1}$ is the first dissociation constant corresponding to the neutralization of carboxylate group :

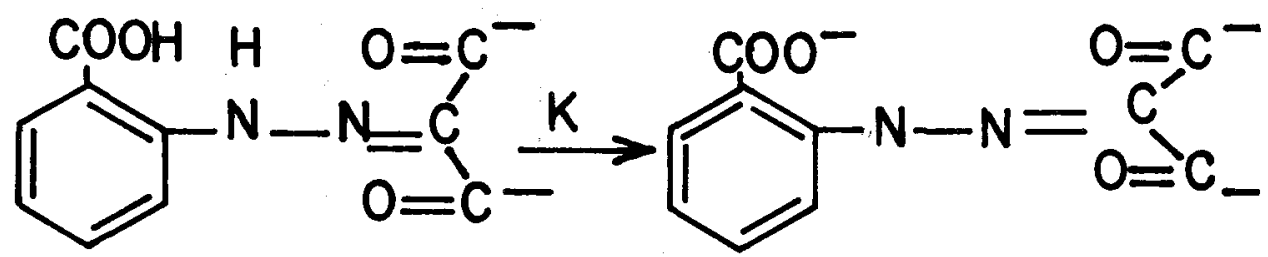

$\mathrm{Ka}_{2}$ is the second dissociation constant arises from the dissociation of hydrazo group.

The overall stability constants of complexes were calculated by Bjerrum's and Albert's methods ${ }^{(4)}$.

The glass electrode was used to measure the concentration of hydrogen ion, in absolute methanol, following the procedure used by Ismailov et $\mathbf{a l}^{(6)}$.

\section{Results and Discussion}

The overall stability constants " $\log B_{2}$ " for $1: 1$ and 2:1 complexes of organic 
ligands and lanthanide ions are summarized in table 1 . The data were subjected to least square analysis. $\log B_{2}$ and standard deviation were extracted using twelve measurements. It is seen that the stabilities of the complexes formed between the studied ligands and the lanthanide increase as follows

\section{2-CPHDEM $>2$-CPHBA $>2-$ CPHAA $>3$-CPHDEM}

Table 1

Stability Constants of Lanthanide Complexation By

2-CPHAA, 2-CPHBA, 2-CPHDEM, and 3-CPHDEM

$$
[\mathrm{Lig}]=5 \times 10^{-3} \mathrm{M},[\mathrm{M}]=2.5 \times 10^{-3} \quad \mathrm{~V}=50 \mathrm{ml}
$$

\begin{tabular}{|c|c|c|c|c|}
\hline \multicolumn{5}{|c|}{$\log B_{2}$} \\
\hline & $\begin{array}{c}2-C P H A A \\
p K_{1}=6.08 \pm 0.02 \\
p K_{2}=12.15 \pm 0.05\end{array}$ & $\begin{array}{l}2-C P H B A \\
6.41 \pm 0.03 \\
11.86 \pm 0.04\end{array}$ & $\begin{array}{c}2-C P H D E M \\
6.16 \pm 0.02 \\
13.69 \pm 0.06\end{array}$ & $\begin{array}{c}3-C P H D E M \\
6.49 \pm 0.03 \\
11.68 \pm 0.04\end{array}$ \\
\hline La & $24.52 \pm 0.02$ & $24.85 \pm 0.04$ & $28.95 \pm 0.03$ & $23.86 \pm 0.03$ \\
\hline $\mathrm{Ce}$ & $24.75 \pm 0.03$ & $25.15 \pm 0.04$ & $29.15 \pm 0.02$ & $24.00 \pm 0.03$ \\
\hline $\operatorname{Pr}$ & $24.91 \pm 0.02$ & $25.30 \pm 0.04$ & $29.30 \pm 0.02$ & $24.29 \pm 0.04$ \\
\hline $\mathrm{Nd}$ & $25.16 \pm 0.04$ & $25.41 \pm 0.10$ & $30.00 \pm 0.02$ & $24.37 \pm 0.03$ \\
\hline Sm & $25.93 \pm 0.03$ & $25.98 \pm 0.10$ & $30.63 \pm 0.02$ & $24.56 \pm 0.05$ \\
\hline Eu & $25.92 \pm 0.06$ & $26.09 \pm 0.10$ & $30.88 \pm 0.04$ & $25.00 \pm 0.04$ \\
\hline Gd & $25.83 \pm 0.04$ & $26.00 \pm 0.10$ & $30.68 \pm 0.05$ & $24.97 \pm 0.04$ \\
\hline $\mathrm{Tb}$ & $25.90 \pm 0.03$ & $26.40 \pm 0.10$ & $30.60 \pm 0.03$ & $25.11 \pm 0.04$ \\
\hline Dy & $25.85 \pm 0.06$ & $26.57 \pm 0.04$ & $30.10 \pm 0.02$ & $25.63 \pm 0.02$ \\
\hline Ho & $26.07 \pm 0.06$ & $26.34 \pm 0.10$ & $30.25 \pm 0.02$ & $25.91 \pm 0.03$ \\
\hline $\mathrm{Er}$ & $26.30 \pm 0.06$ & $26.59 \pm 0.10$ & $30.47 \pm 0.04$ & $26.27 \pm 0.02$ \\
\hline $\mathrm{Tm}$ & $27.06 \pm 0.03$ & $27.32 \pm 0.10$ & $30.75 \pm 0.04$ & $26.72 \pm 0.03$ \\
\hline$Y b$ & $27.66 \pm 0.04$ & $27.66 \pm 0.06$ & $31.35 \pm 0.02$ & $27.32 \pm 0.10$ \\
\hline Lu & $27.20 \pm 0.04$ & $27.57 \pm 0.06$ & $31.00 \pm 0.02$ & $26.61 \pm 0.02$ \\
\hline
\end{tabular}


It was found that the stability of $2-\mathrm{CPHDEM}-\mathrm{Ln}^{3} \quad$ complexes is higher than that of 3-CPHDEM-Ln ${ }^{3}$ by nearly 5 units. This can be attributed to the higher basicity ( $\mathrm{pK}$ 's) of ortho ligand, leading to the increase in electronegativity of ketonic oxygen in 2-CPHDEM that of $3-$ CPHDEM ligand. Thus, a greater bond attraction will be produced between the lanthanide cations (lanthanide complexes are mainly ionic) and 2-CPHDEM, leading to greater stability of the 2CPHDEM - lanthanide complexes. Also the greater stability of 2-CPHDEM complexes may be attributed to the sharing role of the carboxylic group in the 2-position in coordination compound than that of the carboxylic group in the 3-position.

A small increase of the stability values of 2-CPHBA lanthanide complexes over that of 2-CPHAA-lanthanide complexes was observed. This may be due to the higher shielding effect of the phenyl group compared to that of the methyl group, and the basicity of the ligands is nearly the same, (pK's $=18.27 \& 18.23$ ) for 2-CPHBA and 2-CPHAA, respectively.

Fig. 1 shows the overall stability constants of complexes, plotted against the atomic number of the lanthanides. Instead of the expected linear increasing course, a break is observed, around gadolinium (gadolinium-break), whereas the first part from lanthanum to europium increases linearly and the second part, gadolinium to erbium is nearly constant. A gradual increase of stability constant of complexes with atomic number is observed, from erbium to lutetium. The deviation of these ligands from linearity is not piculiar, but it seems to be common for most rare earth complexes with different chelating agents such as acytylacetone (1), benzoylacetone, ${ }^{(7)}$ tropolone ${ }^{(8)}, \mathrm{N}$-hydroxyethylenediamine triacetic acid ${ }^{(9)}$, etc. This agreement in the behaviour of the studied ligands with the other one cited in literature ${ }^{(1.2 .7-10)}$, is due to the similarity in presence of several sites as, two carbonyls, hydrazo and carboxylic groups in the studied ligands. 
Table 2

" $\log \mathrm{B}_{2}$ " for europium complexes in methanol.

\begin{tabular}{|c|c|c|c|c|}
\hline $\begin{array}{c}\text { Chelating } \\
\text { agents }\end{array}$ & $\begin{array}{c}\text { Ionic } \\
\text { strength }\end{array}$ & $T^{\circ} \mathrm{C}$ & $\log \mathrm{B}_{2}$ & Solvent \\
${ }^{*} \mathrm{aa}^{(11)}$ & 0.10 & 23 & 14.39 & $80 \%$ Methanol \\
${ }^{* *} \mathrm{BA}^{(12)}$ & 0.10 & 23 & 14.47 & $80 \%$ Methanol \\
BA $^{(13)}$ & 0.10 & 23 & 19.80 & $100 \%$ Methanol \\
2 - CPHAA & - & 30 & 25.92 & $100 \%$ Methanol \\
2-CPHBA & - & 30 & 26.09 & $100 \%$ Methanol \\
$2-$ CPHDEM & - & 30 & 30.88 & $100 \%$ Methanol \\
3-CPHDEM & - & 30 & 25.00 & $100 \%$ Methanol \\
\hline
\end{tabular}

* AA=acetylacetone, ${ }^{* *} \mathrm{BA}=$ Benzoylacetone 


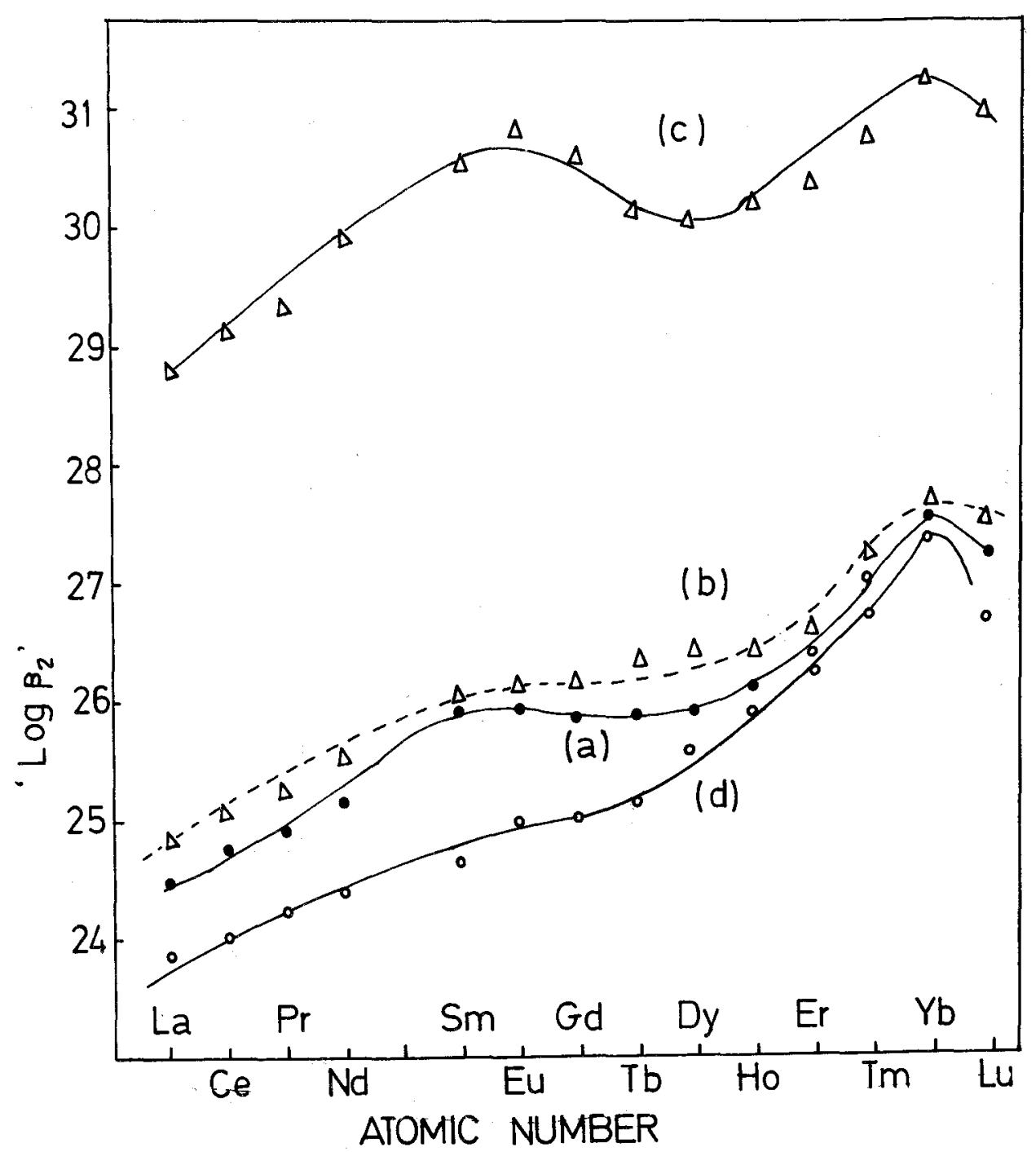

Fig. 1: The relationship between atomic number and " $\log \mathrm{B}_{2}$ " for trivalent lanthanides with 2-CPHAA (curve a); 2-CPHBA (curve b); 2-CPHDEM (curve c); and 3-CPHDEM (curve d).

Figure (2) represents the relation between the overall stability constants and the total basicity ( $\Sigma \mathrm{pK}_{1}+\mathrm{pK}_{2}$ ) for europium complexes with organic ligands. The straight line obtained reflects the ionic nature of the ligands, indicating that the ligands release the same number of molecules of water of hydration upon coplexation. This leads to the conclusion that the organic ligands form the same chelate structure upon complexation. 


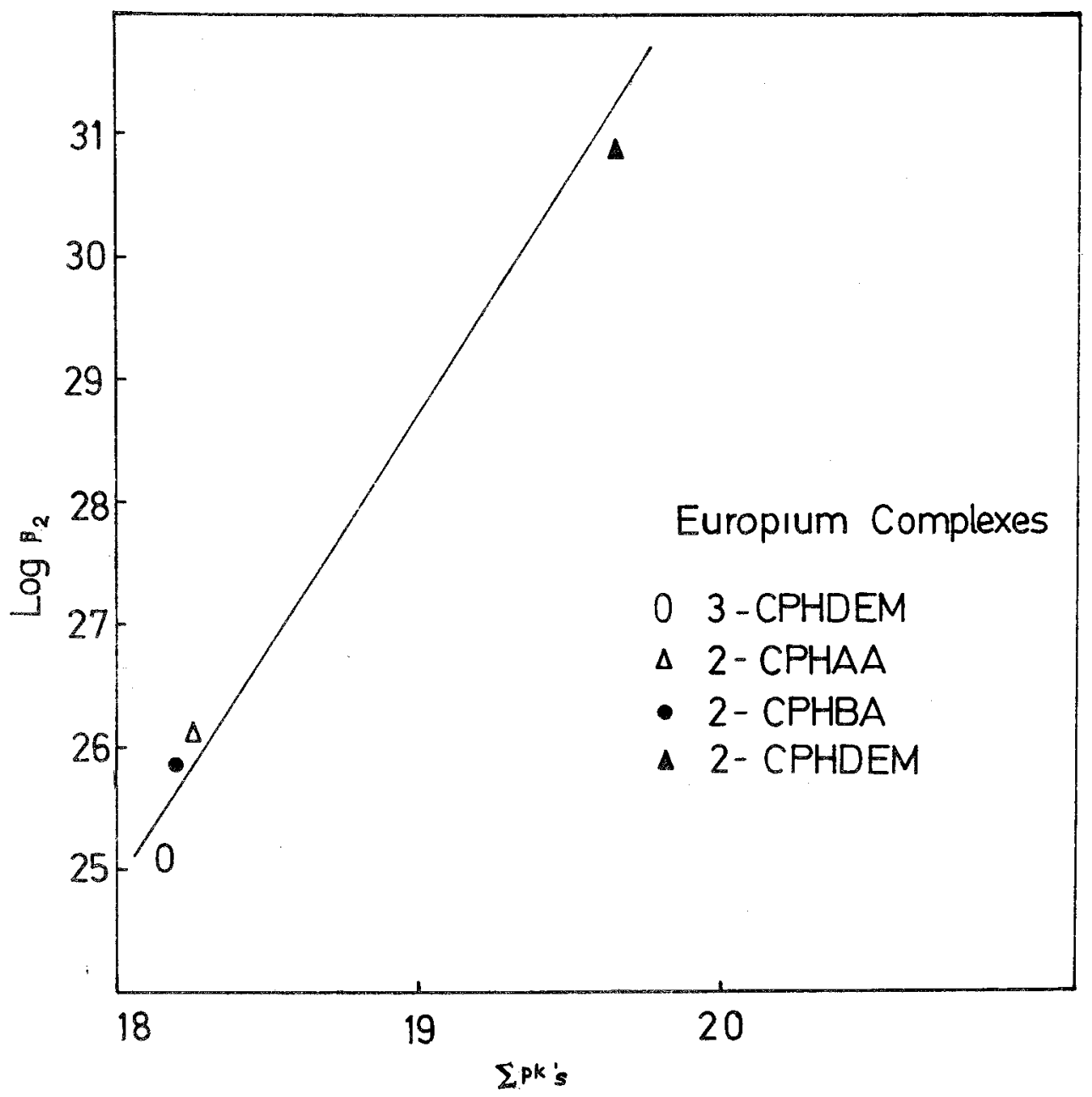

Fig. 2: Correlation of $\log B_{2}$ of Eu (III) Complexes and $\Sigma$ pK's of the ligands.

The relatively higher " $\log B_{2}$ " of the complexes of the studied ligands and lanthanide cations may be due to the presence of several coordination sites in the ligands. Moreover, the use of $100 \%$ methanol at zero ionic strength, increases the solvation effect of ligands (see Table 2). 


\section{REFERENCES}

1. I. Grenthe and W. C. Fernelius, J. Am. Soc., 82, 6258, (1960).

2. A. Dadgar and G. R. Choppin, J. Coord. Chem., 1,179, (1971).

3. G. A. El-Inany, A. A. Raman, B. A. El-Shetary (to be puplished).

4. A. Albert and E. P. Serjeant "Ionization Constants of Acids and Bases" p.p. 36, 162-164. London, Methuen and Co. Ltd. (1962).

5. J. Bjerrum "Metal amine formation in aqueous solution" $P$. Haasse and Son, Copenhagen, (1941).

6. N. A. Ismailov, "Elektrokhimiya Rostvoorov" (The electro-chemistry of solution). Izd. Khar'kov. Univ., Khar'kov (1959).

7. N. K. Davidenko and A. A. Joladkov, J. Inorg. Chem. (USSR), 12, 633 (1967).

8. D. L. Campoel and T. Moeller, J. Inorg. Nucl. Chem., 31, 107 (1969).

9. F. H. Spedding, J. E. Powell and J. Wheelwright, J. am. Chem. Soc., 78, 34, (1956).

10. R. Stampfli and G. R. Choppin, J. Coord. Chem. 1, 173, (1971).

11. A. A. Joladkov, N. K. Davidento, J. Inorg. Chem. (USSR), 13, 3223 (1968).

12. N. K. Davidento, A. A. Joldkov, ibid, 12, 1195 (1967).

13. A. A. Joladkov, N. K. Davidento, ibid, 12, 3066 (1967). 


\section{حسابات ثوابت الاستقرار لمتراكبات اللنثانيدات مع الآنو - بيتا ـ داي كيتونات}

محمد سمير عبد المعز - جابر العناني - عاطف رمضان - بشير الشطيري

$$
\text { كلية العلوم - جامعة قطر }
$$

وكلية التربية - جامعة عين شمس

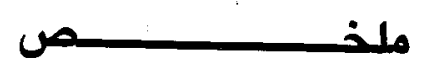

قد ودث ثوابت الاستقرار لمتراكبات كاتيونات اللنثانيدات الثلاثية مع بعض ليجاندات

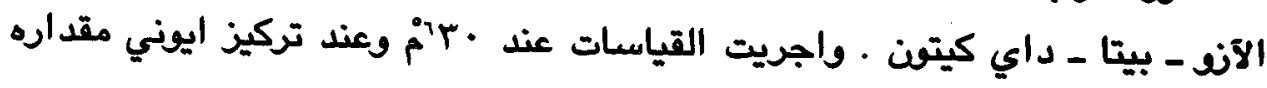

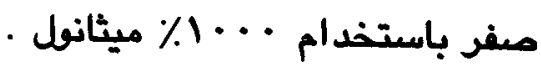

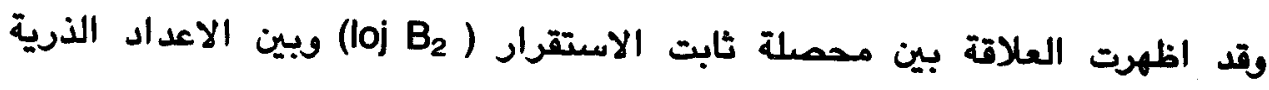

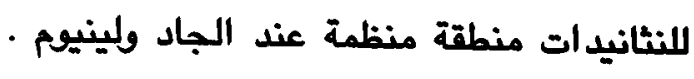

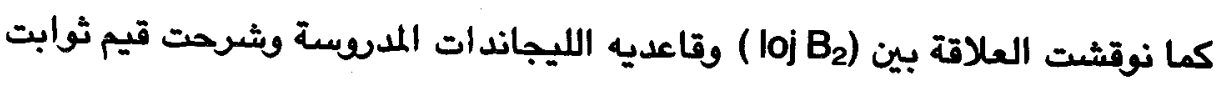

الاتزان .

وقد أظهرت الدراسة من خلال حساب قيم ثوابت الاستقرار القابلية الكبيرة

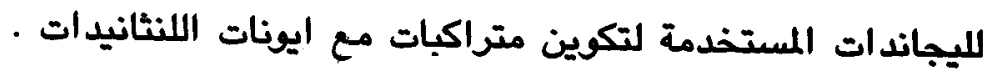

